\title{
Electro-Pneumatic Sepak-Takraw Ball Pitching Device
}

\author{
Roy S. Alcazar ${ }^{1}$, Julius A. Cajipe ${ }^{1}$, Christian M. Tolentino ${ }^{1}$, \\ Enrico Paul F. Puyo, BSc-Electrical Engineering ${ }^{2}$, Wilfred Ralph G. Gomez, MM-HRM ${ }^{3}$ \\ ${ }^{1}$ Student, BSc Industrial Technology, Major In Electrical Technology, \\ ${ }^{1}$ Laguna State Polytechnic University, Laguna, Philippines \\ ${ }^{2}$ Instructor, BSc Industrial Technology, Laguna State Polytechnic University, Laguna, Philippines \\ ${ }^{3}$ Instructor, BSc Industrial Technology, Research Unit Head- College of Industrial Technology \\ ${ }^{3}$ Laguna State Polytechnic University, Laguna, Philippines
}

\begin{abstract}
The proposed study aimed to design and develop an "Electro-Pneumatic Sepak-Takraw Ball Pitching Device". It is primarily concerned with designing a device that can pitch a ball simultaneously from a specified height. It has a manual feature that makes the pitching being controlled by another player thru a set of pushbuttons, and an automatic feature that enables the Sepak-Takraw ball being launched simultaneously controlled via smart phone. After the series of trials, several alterations were made in the microcontroller program and mechanical design for the automatic and manual feature. Results revealed that the developed prototype passed all the requirements and recommended to be used as a training device. Also, researchers recommend some design considerations for the improvement of the device, and these were: to add more electronic features to the device; and to develop an automatic swing feature: up, down, left, and right to have a realtime variety of pitching angles. Researchers also recommend an oil-less/ silent type compressor with the big reservoir to minimize noise, increased compressed air efficiency to effectively pitch the ball without delay, and decreased power consumption due to simultaneous pumping and use of compressed air.
\end{abstract}

Key words: $\begin{gathered}\text { Sepak-Takraw, } \\ \text { Automatic } \\ \text { Pitching, }\end{gathered}$ Electro-pneumatic,
Eling Device,

Microcontroller

\section{INTRODUCTION}

Nowadays, innovative products, services, and deliverables were introduced to the market. Modern technology plays an important factor in making things faster to become more productive. In order to continue the production of new devices, researchers keep on developing new products and services that would further enhance human lives. In the field of ball games, there are numerous devices that were invented to do a specific task; and that is, to hone the skills of these athletes. A research published in Procedia, Journal of Computer Science, by Kos et al. (2018), entitled "The Role of Science and Technology in Sports" it was emphasized that $21^{\text {st }}$ century skills in sports were achieved using technological trends and different innovative challenges such as Internet of Things (IoT), smart sport equipment, and real-time biofeedback systems and applications. Sepak-Takraw, a recreational and popular sport in the Philippines, were taught and played in the universities during tournaments. Sepak-Takraw or kick volleyball is a sport native to Southeast Asia. It differs from the similar sport of Foot volley in its use of a rattan ball and only allowing players to use their feet, knee, chest, and head to touch the ball. It is a popular sport in Malaysia, Thailand, and Indonesia. Practicing this sport in the context of efficiency, flexibility, and independence using the fluid power of the Pneumatic technology are the key factor in the study being proposed.

\section{LITERATURE REVIEW}

The proposed study was anchored on a research relating to technology enhanced teaching and coaching published on the International Journal of Performance Analysis in Sport, by Sujae et.al (2008). In the research, it specifically identified that technology plays an important role in detecting and 
evaluating the two complex serve skills namely: the power smash and the normal relay. The recorded methods were done employing the use of high-speed optical camera systems, thus technology in this phase is an intervention in the native sport Sepak-Takraw.

Another study conducted by A. Rashid AZIZ et al. (2003) published in the International Journal of Applied Sports Sciences, relating to an assessment of the physical demands of the Sepak-Takraw sport and the physiological profiles of the elite players. The temporal characteristics of matches namely: duration of rally, recovery, set and match; physiological responses: heart rate $(\mathrm{HR})$ and blood lactate (La) of the players during matches were recorded. The data suggested a dominant contribution of the anaerobic energy systems in Sepak-takraw. There were no significant differences among the three positional roles of the spikers, feeders and servers in all the measures, except for height. The Sepak-takraw player have excellent leaping power and ability to execute high - intensity anaerobic work, but lower aerobic fitness. The players' fitness attributes corresponded well with their physiological reactions and the temporal characteristics through the match. Using the data from this study, it is empirical to develop such amateur players using the proposed device to become an elite player.

In the context of safety, the Sepak-takraw balls were examined and defined to be typically made of plastic. Lately new balls made of plastic infused with rubber was introduced. In the study of Taha, Z. (2008), which focused on the impact of Sepak-takraw Balls on the Head published in International Journal of Sports Science and Engineering. There were measures being developed to quantify the Head Impact Power of Sepak-takraw balls. It was found that using different balls results in exclusively two different results. The balls made of plastic infused rubber has 4 times more probability of causing mild brain traumatic injury when fallen from a depth of $3.5 \mathrm{~m}$. The highlight of their study states the importance of the safety of an athlete when designing sports equipment even as simple as a plastic ball.

Also anchored to the context of wellbeing of the Sepak-takraw sport, in the study conducted by Silalertdetkul (2016), He expressed the finding about the Sepak-Takraw practice contributes to an increase in circulating interleukin-6 and creatine kinase concentrations that are produced from human muscle, secreted into the blood stream in response to muscle contractions. It is suggested that the intensity and duration of the practice should be taken into consideration to balance the secretions of the said hormone-like substance and stay healthy.

Another study relating to the pre-identification of elite members of Sepak-Takraw sport by Rezaei, M. et al. (2013). The results of their study showed that the differences between the members may cause by the diverse roles and obligations while playing and different exercise methods which detailed for each position. In contrary, another factor to describe the eliteness of the players was anchored on the study conducted by Sujae, Iian and Koh, Michael (2008) in gaining insights on Sepak-Takraw serves, technique differences, and establish factors influencing ball speeds. The best successful kuda and sila serves of nine (9) elite male national Sepak-Takraw players were recorded using seven(7) ProReflex 1000 optical cameras operating at $240 \mathrm{~Hz}$. The two serving techniques, namely: kuda and sila serves are nonplanar kicking techniques demonstrating a no proximal-to-distal classification. Variances in kicking kinematics $(\mathrm{P}<0.05)$ signify differences between techniques. Compared with the sila, the kuda kicking limb is a lengthier rigid segment that moves over a larger range of gesture. Greater range of motion enables the longer rigid kuda lever to create greater kicking angular momentum, resulting in greater effect impulse. This immediately deciphered to the significantly higher ball release speeds based on the impulse-momentum association. Coaching implications include refining hip joint elasticity and functioning on a fluid drive of a lengthier rigid segment kicking method.

Sports psychologists have long believed that high levels of competitive state anxiety during competition are harmful, worsening performance and even leading to dropout. The instrument used for the study comprised of a 27-item Competitive State Anxiety Inventory-2 and The Psychological Performance Inventory which had been distributed during sport festival. The sample consisted of national athletes $(\mathrm{N}=25)$, state athletes $(\mathrm{N}=19)$, district athletes $(\mathrm{N}=20)$ and university athletes $(\mathrm{N}=14)$. The results revealed that the elite group or national athletes exhibited lower levels of competitive state anxiety. It is suggested to use the present findings to recommend coping strategies to the different universities and district level athletes that are appropriate for dealing with their athletes' competitive state anxiety. (Parnabas, 2015) 

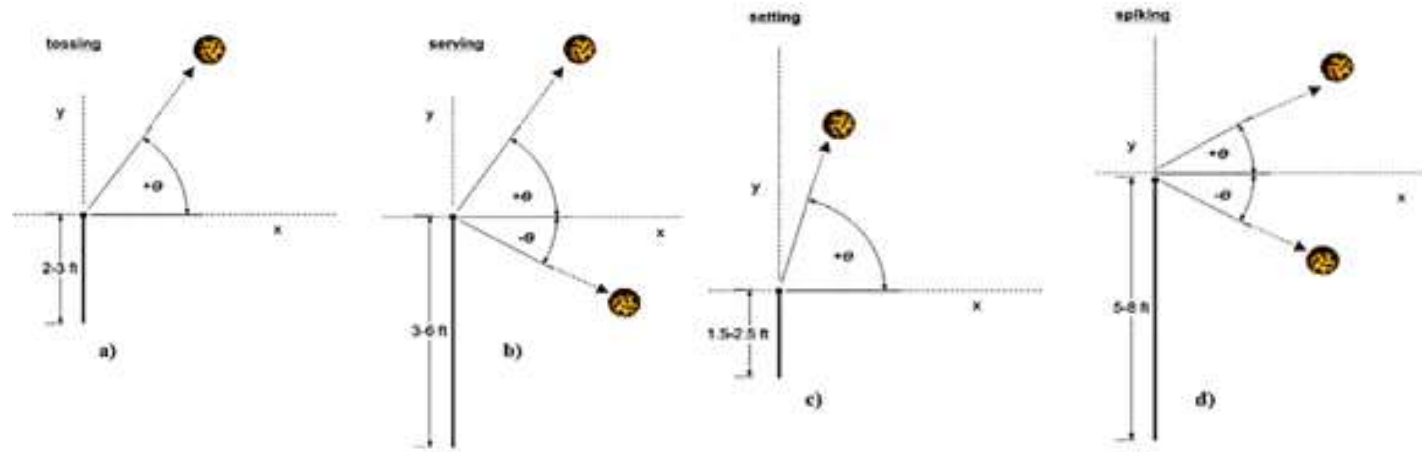

Figure 1. Illustration of Launching Point and Launching Angle of Sepak-Takraw Ball Movement in a)Tossing b) Serving c) Setting d) Spiking

As seen in figure 1, the four movements can be described as follows:

$>$ Tossing: Ball is tossed by the tosser position from 2-3 feet high with a positive angle $(+\theta)$ in reference to the horizontal plane, to the server position on the same side of the court.

> Serving: Ball is kicked by the server from 3-6 feet high with a positive $(+\theta)$ or negative $(-\theta)$ angle in reference to the horizontal plane, to the opposing side of the court.
Setting: Ball is kicked from 1.5-2.5 feet high with a positive angle $(+\theta)$ in reference to the horizontal plane, to another player in the spiker position on the same side of the court.

Spiking: Ball is spiked by spiker from 5-8 feet high with a positive angle $(+\theta)$ and negative angle $(-\theta)$ in reference to the horizontal plane, over the net to the opposing side of the court.

Table1. Basic Kinematic Data of Four Movements in Sepak-Takraw Movements

\begin{tabular}{|c|c|c|c|c|c|c|}
\hline \multirow{2}{*}{ Movements } & \multicolumn{2}{|c|}{$\begin{array}{c}\text { Ball position } \\
\text { (ft.) }\end{array}$} & $\begin{array}{c}\text { Ball travel distance } \\
\text { (ft.) }\end{array}$ & \multicolumn{2}{c|}{$\begin{array}{c}\text { Ball launch angles } \\
\text { (degree) }\end{array}$} \\
\cline { 2 - 7 } & Releasing height & End height & Min. & Max. & Min. & Max \\
\hline Tossing & $2-3$ & $3-6$ & 12.2 & 16.2 & 0 & 60 \\
\hline Servicing & $3-6$ & $3-6$ & 13 & 36.7 & -30 & 60 \\
\hline Setting & $1.5-2.5$ & $5-8$ & 2 & 22 & 30 & 80 \\
\hline Spiking & $5-8$ & $5-8$ & 5 & 44 & -30 & 30 \\
\hline
\end{tabular}

\section{CONCEPTUAL FRAMEWORK}

The figure shown on the next page are the Input or the project schedule, the Process or the project procedures, and the Output of the study which is development of the device.

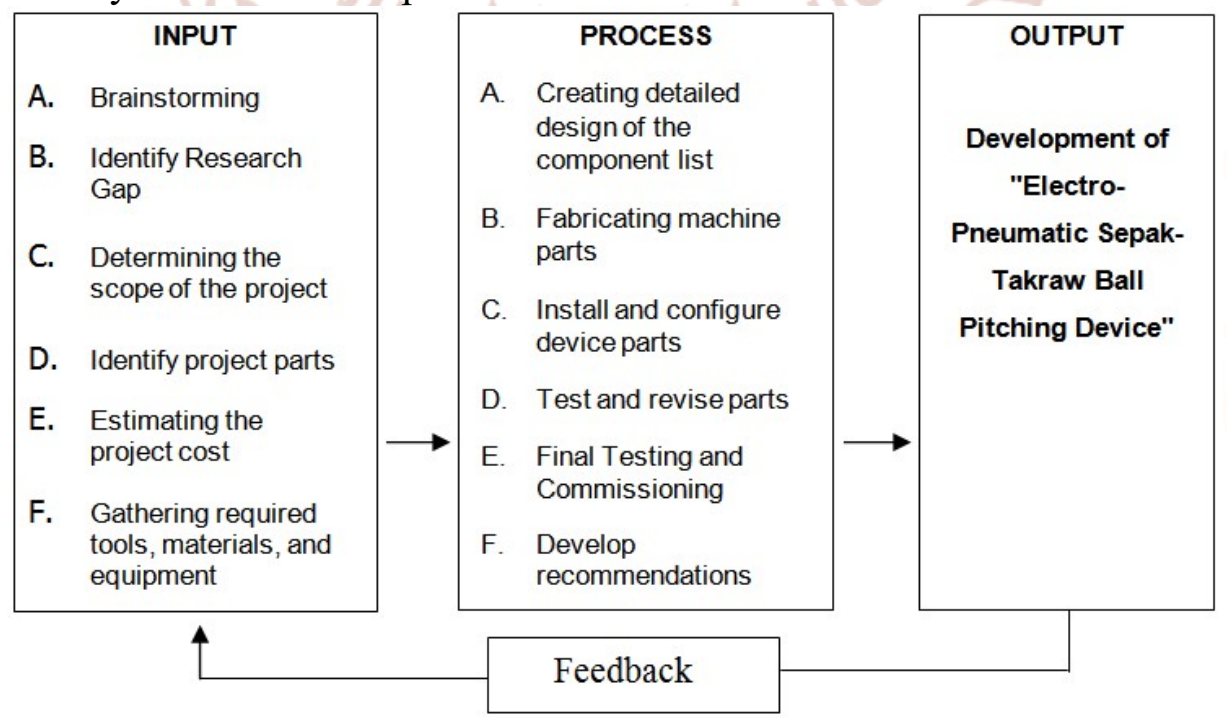

\section{Objectives}

Figure2. Schematic Diagram showing the Project Flow

1. To design and develop pitching device that utilizes fluid power from compressed air. 
2. To include manual feature for the utilization of the device.

3. To incorporate automatic feature employing the use of a micro-controller for independent and simultaneous pitching mechanism.

4. To test the operational capability of the device.

\section{Scope and Limitation of the Study}

1. To have a manual and automatic control to pitch.

2. Limited of five (5) balls can be loaded.

3. The device have an adjustable angle horizontally up to $+/-360$ degree.

4. The device can change angle vertically, +10 to + 50 degrees only and can pitch a velocity of $20 \mathrm{Km} / \mathrm{h}$ up to $80 \mathrm{Km} / \mathrm{h}$.

5. Adjustable air-pressure specification for the Air Compressor: maximum of 10 bar or 145 psi.

\section{Significance of the Study}

The findings of the study may have significant contribution to the following:

Athletes: The use of engineered practice equipment will enable them to enhance their practice and improve safety conditions.

School Administrators: The results of the study would be of great help for them to plan appropriate action relative to the offering of course program.

Curriculum Planners: This study would provide substantial information in enhancing the curriculum by planning some educational reforms for effective implementation that would address the need of the industry.

Future Researchers: The results of this study would serve as a basis to further studies regarding assessment of technical skills in the industrial workplace.

\section{Methodology}

The scope of this research includes gathering kinematic data on the types of ball motion generated in Sepak-Takraw and using this data and other research in order to design and build an automatic Pitching machine for Sepak-Takraw to be used for training athletes.

\section{Research design}

This study aims to develop and evaluate the qualities of Automatic Pitching Machine for Sepak-Takraw.

\section{Project Design}

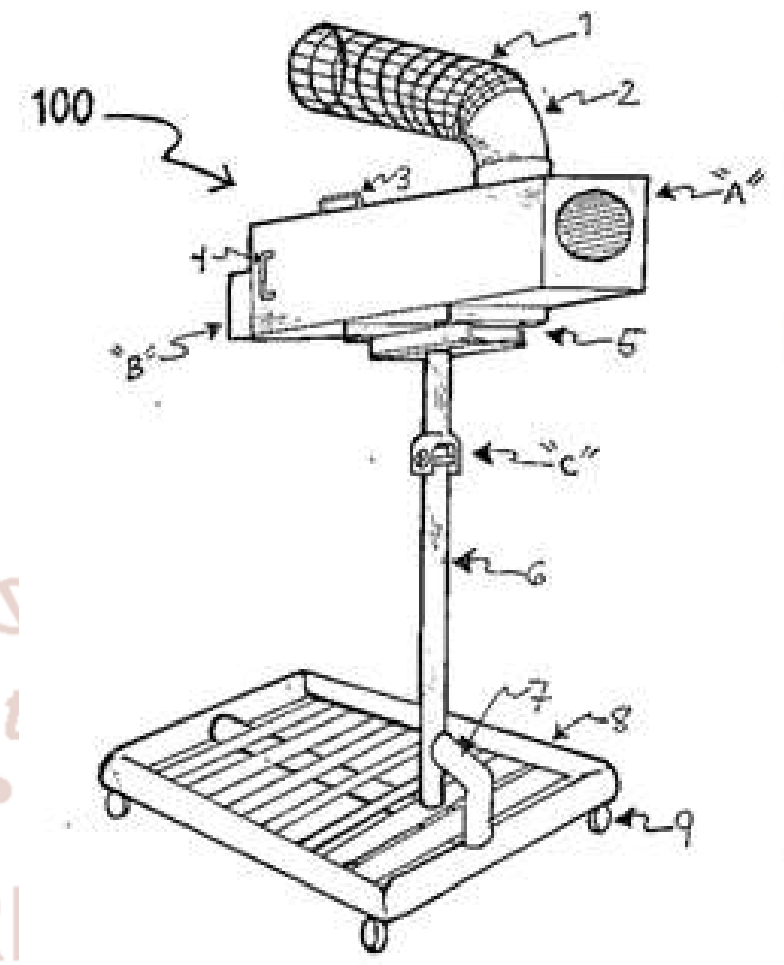

Figure3. Perspective View of the Electro-Pneumatic Sepak-Takraw Ball Pitching Device

As shown on figure 3 above is the perspective view of the whole device (100). The magazine (1) which serves as a queue storage for the Sepak-Takraw ball and is located at the top most portion. The connecting pipe (2) which is attached right next to the said magazine (1) routes the Sepak-Takraw ball to the Part "A". The Part "A" has several parts inside which will be further explained at the discussion of Figure 4 on the next page. Also, there is a access handle (3) located at the top covering of Part "A" serves as an aide in opening the cover above. Another handle, the launcher handle (4) installed perpendicular to access handle (3) which serves as an aide for stabilizing the vibration of Part "A".

At the back part of Part " $A$ ", is the Part " $B$ " which is installed in parallel with the launcher handle (3) will be further explained in the discussions of Figure 5 . The bracket (5) located below Part " $\mathrm{B}$ " that is welded to the Part "A" which provides support for the actuation of mechanism. Along with bracket (5) installed perpendicularly is Part " $\mathrm{C}$ " to enable a tilting mechanism for a variety of pitching angles. Attached below the Part "C" is the metal pipe (6) that provides structure for the whole device. A support frame (7) is connected right next to the metal pipe (6) to provide support to the structure. A rectangular base (8) is 
where the support frame (7) is mounted, it is a flat surface where an external air-compressor can be placed. A set of wheels (9) provides portability attached to the bottom part of the rectangular base (8).

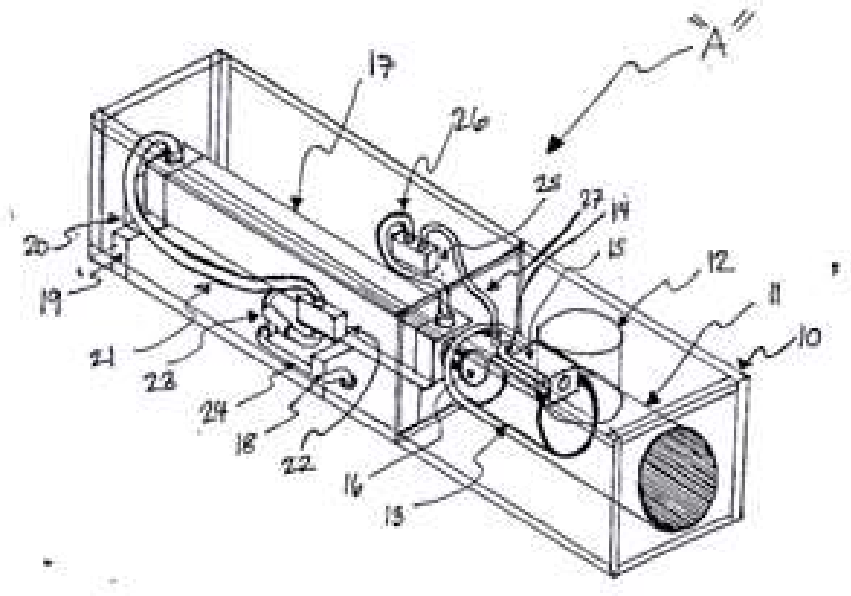

Figure4. Isometric View of Detailed Part "A"

As shown on figure 4 on the previous page is the detail of the Part " $A$ " which consist of several parts. The launcher frame (10) is a rectangular frame made of iron steel and was welded to provide adequate strength and storage to the structure. A cylindrical bin (11) is located inside the center portion of the launcher frame. It is primarily used as a guideway of the Sepak-Takraw ball upon its launch. A connecting pipe (12) connected in perpendicular to the cylindrical bin (11) is used as a connector and a passageway for the queued balls. A guide pipe (13) connected in perpendicular to the connecting pipe (12), also inside the cylindrical bin (11) used to isolate the movements of the actuator. A reloading actuator (14) located in parallel to the guide pipe (13) and cylindrical bin (11), which controls the queuing of the incoming SepakTakraw balls. A slider (15), connected to the reloading actuator rod's tip (14) provides an interlocking mechanism for ball queue. Another part similar to the slider (15) is the pitching actuator rod's tip (16), located inside the cylindrical bin (11) which directly provides physical contact to the SepakTakraw ball upon launching.

Another part, where the pitching actuator rod's tip (16) is installed, the pitching actuator (17), a pneumatically driven actuator that ultimately pushes the Sepak-Takraw ball and automatically returns to its retracted position. The bottom-front bracket (18), which provides support for the movements and actuation of the front-side of the pitching actuator (17). A similar part on the bottom back side of the pitching actuator is the bottom-back bracket (19), also secures stability of the movements caused by actuation. A support bracket (20), attached to the bottom-back bracket (19) serves as a metal reinforcement holding the pitching actuator (17).

The pitching actuator inlet hose (21) situated near the support bracket, is connected to the pitching actuator (17) that provides air supply for the device. A pitching actuator solenoid valve (22), connected to the pitching actuator inlet hose (21) shifts the flow of air to make the pitching actuator (17) perform the pitching and retracting mechanism. A T-connector (23) provides a compressed air-supply to the pitching actuator hose (21). Another part, the air-supply hose (24) connected from an external air compressor provides air to the system. The reloading actuator solenoid valve (25) also uses supply air coming from the air-supply hose (24), is responsible for the actuation of the magazine actuator (14). Another hose connected to the reloading actuator solenoid valve (25) is the pitching actuator outlet hose (26) which is responsible for the passage of exhaust air from the pitching actuator (17). Also, another hose situated beside the ejecting actuator outlet hose (26) is the magazine actuator hose (27) which is responsible for the passage of supply and exhaust air of magazine actuator (14).

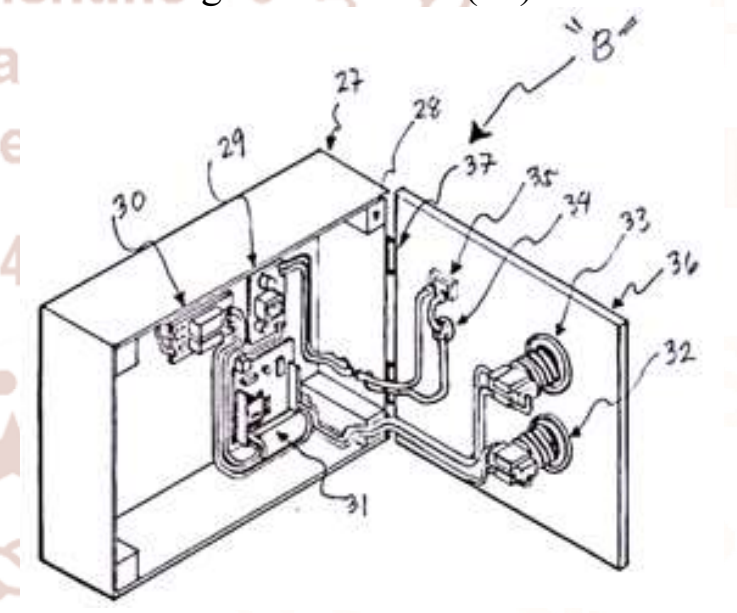

Figure5. Isometric View of detailed Part "B"

As shown figure 5 is the detail of the Part " $\mathrm{B}$ " which consist of several parts. The electronic box frame (27) holds all the electronic components. The support wood (28) is distributed in the four corners of the electronic box frame (27) provides adequate stiffness and improvement to the structure. A power supply (29) situated inside the electronic box frame (27) provides adequate DC supply voltage to all electronic components. Another component, a relay module (30) situated next to the power supply (29) serves as a switching component for the devices associated in Part "A". Another electronic component, a 
microcontroller (31) controls the signals to the system and manipulates the relay module (30). A pitch button (32), whose wires are connected to the said microcontroller (31), influences the signal and is responsible for the pitching mechanism. Situated next to the said pitch button (32) is the reload button (33), which also influences the signal and is responsible for the reloading mechanism. A Red LED (34), situated near to the said reload button (33), indicates the status of the power from the electric supply. A power switch (35), whose wires are connected to the said Red LED (34), controls the energizing and de-energizing of the system. A framed door (36), where the components like the said power switch (35), Red LED (34), pitch button (32), pitch button (32) are mounted. A hinge (37), which connects the said frame door (36) to the electronic box frame (27).

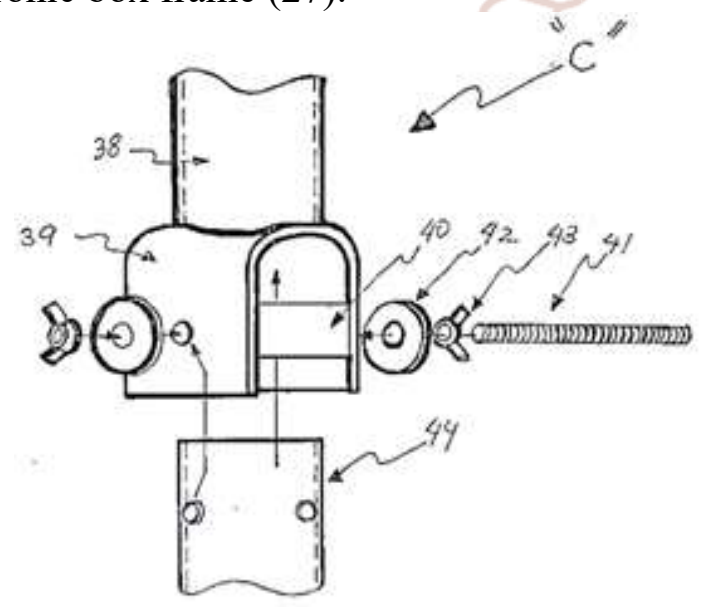

Figure6. Exploded View of detailed Part "C"

As shown on the figure above is the detail of the Part "C" which consist of several parts. The metal pipe (38) connects the whole Part " $C$ " to the Part " $B$ ". Another mechanical part, the U-bar frame (39) where it is welded to the said metal pipe (38) provides a mounting for the other components. A reinforcement flat bar (40) where it is welded in between the U-bar frame (39), provides adequate support for the material strength of the said frame and also clamps the standpipe (44). A screw bar (41) is inserted in-line with the said reinforcement flat bar (40) and also inserted to the hole of U-bar frame (39) that primarily responsible for the attachment of the metal pipe (38) and the standpipe (44). Another component, a washer (42) which is inserted in the screw bar (41) provides a space and reinforced fitting for the locking component, the butterfly nut (43). The said nut, provides adequate force to lock the U-bar frame (39) and the standpipe (44).

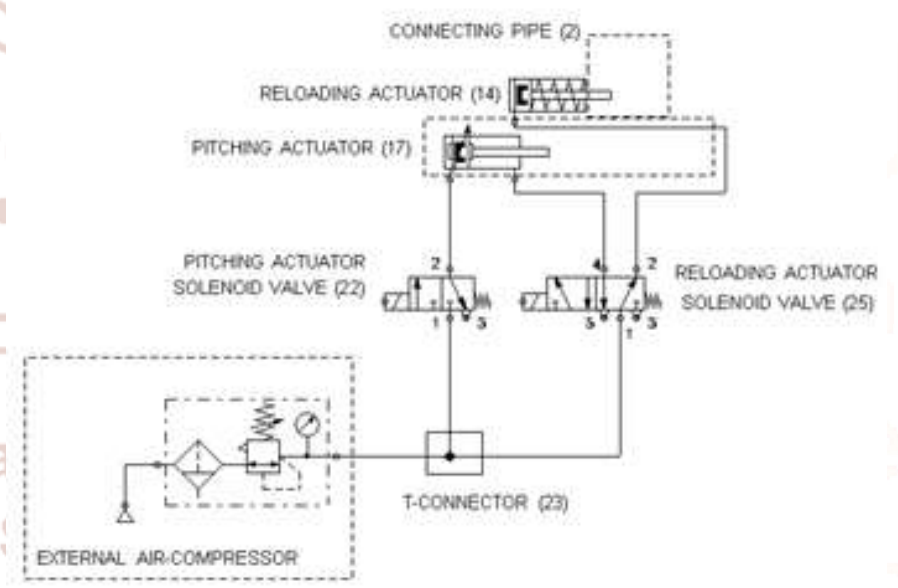

Figure7. Electro-Pneumatic Circuit of the Prototype

The figure shown above shows the Electro-Pneumatic circuit which consist of the following elements: External Air-Compressor with filter and oil separator, T-connector, Solenoid Valves, Double-Acting Cylinder, and a Single Acting cylinder.

Table2. Supplies and Materials

\begin{tabular}{|l|l|}
\multicolumn{1}{|c|}{$\begin{array}{c}\text { SUPPLIES \& } \\
\text { MATERIALS }\end{array}$} & \multicolumn{1}{c|}{ FUNCTIONS AND THEIR USES } \\
\hline Double acting cylinder & Used to pitch the ball \\
\hline Single acting cylinder & Used to avoid continuous re-load of ball \\
\hline Air compressor & It is used as the supply of the cylinders \\
\hline Solenoid valves & to cut/allow the flow of air from compressor going to the cylinders \\
\hline Quick exhaust valve & $\begin{array}{l}\text { It is used to boost the force of pitching } \\
\text { it is also used as the signal of the machine before pitching by it sound }\end{array}$ \\
\hline Air tubings & Used to flow the air and attached to the air fittings \\
\hline Air fittings & Used as the socket of the hose \\
\hline Wemos D1 & it is Micro controller with Wi-Fi hotspot used as the brain of the Wi-Fi control \\
\hline Ultrasonic distance sensor & Used to detect if the machine is loaded or not \\
\hline Relay module & It is used to trigger the solenoid valves in Wi-Fi control \\
\hline
\end{tabular}


International Journal of Trend in Scientific Research and Development (IJTSRD) ISSN: 2456-6470

\begin{tabular}{|l|l|}
\hline Single switch & it is used to close/open the circuit of the machine \\
\hline Push button & $\begin{array}{l}\text { This will trigger the solenoid valves if the user is locked of knowledge to use } \\
\text { the Wi-Fi control }\end{array}$ \\
\hline Metal tube & Used to create the body and stand of the machine \\
\hline Metal angle bar & Used to create the base of the head \\
\hline Metal flat bar & Used to serve as a platform of the machine \\
\hline Ply wood & It is used to cover the base of the head \\
\hline PVC & Used as the rail of the ball \\
\hline Metal screen & Used as the ball hopper \\
\hline
\end{tabular}

Table3. Bill of Materials

\begin{tabular}{|c|c|c|c|c|}
\hline QTY & UNIT & DESCRIPTION & $\begin{array}{c}\text { UNIT } \\
\text { PRICE } \\
(\text { Php) }\end{array}$ & $\begin{array}{l}\text { TOTAL } \\
\text { PRICE (Php) }\end{array}$ \\
\hline 1 & Pcs & $50 \mathrm{~mm}$ bore $\mathrm{x} 350 \mathrm{~mm}$ stroke Double acting cylinder & Php 3,500.00 & Php 3,500.00 \\
\hline 1 & Pcs & $\begin{array}{l}15 \mathrm{~mm} \text { bore } \mathrm{x} 40 \mathrm{~mm} \text { stoke Spring return single } \\
\text { acting cylinder }\end{array}$ & Php 500.00 & Php 500.00 \\
\hline 1 & Pcs & 2HP 8bar 25L Air compressor & Php 5,300.00 & Php 5,300.00 \\
\hline 2 & Pcs & $5 / 2$ solenoid valve $1 / 4$ " port & Php 800.00 & Php 800.00 \\
\hline 3 & Meter & $12 \mathrm{~mm}$ Hose & Php 50.00 & Php 150.00 \\
\hline 8 & Pcs & Air fittings & Php 50.00 & Php 400.00 \\
\hline 1 & PCS & $\begin{array}{l}3 / 8 " X 1 / 4 " X 1 / 4 " \\
\text { Quick exhaust valve }\end{array}$ & Php 1,250.00 & Php $1,250.00$ \\
\hline 1 & Pcs & $\begin{array}{l}\text { Wemos D1 R2 } \\
\text { Wi-Fi shield ESP2866 }\end{array}$ & Php 800.00 & Php 800.00 \\
\hline 1 & Pcs & Ultrasonic sensor & Php 100.00 & Php 100.00 \\
\hline 1 & Pcs & 2 Channel relay module & Php 170.00 & Php 170.00 \\
\hline 1 & Pcs & 5V DC 500mA charger & Php 50.00 & Php 50.00 \\
\hline 20 & Meter & Jumper wire & Php 5.00 & Php 100.00 \\
\hline 1 & Meter & \#16 flat cord extension & Php 100.00 & Php 100.00 \\
\hline 1 & Pcs & $\begin{array}{l}\text { TB-1512 600V } 15 \mathrm{~A} \\
\text { Terminal Block }\end{array}$ & Php 105.00 & Php 105.00 \\
\hline 1 & Pcs & 2" metal tube & Php $1,350.00$ & Php $1,350.00$ \\
\hline 3 & Pcs & 1" flat bar & Php 120.00 & Php 420.00 \\
\hline 1 & Pcs & $1 " x$ 1" angle bar & Php 400.00 & Php 400.00 \\
\hline 1 & Pcs & $1 / 4 "$ plywood & Php 100.00 & Php 100.00 \\
\hline 4 & Pcs & Lock wheel & Php 100.00 & Php 400.00 \\
\hline 1 & Pcs & 6.5 " black PVC & Php 150.00 & Php 150.00 \\
\hline 1 & Meter & 1" x 1" screen wire & Php 105.00 & Php 105.00 \\
\hline 1 & Pcs & 1/16 6.5" Elbow & Php 320.00 & Php 320.00 \\
\hline 1 & Pcs & Solvent & Php 86.00 & Php 86.00 \\
\hline 2 & Pcs & Metal Cutting disk & Php 45.00 & Php 90.00 \\
\hline 3 & Pcs & Sand paper & Php 16.00 & Php 48.00 \\
\hline 2 & Pcs & Drill bit & Php 75.00 & Php 150.00 \\
\hline
\end{tabular}


International Journal of Trend in Scientific Research and Development (IJTSRD) ISSN: 2456-6470

\begin{tabular}{|l|l|l|l|l|}
\hline 1 & Pcs & Bolt and knot & Php 40.00 & Php 40.00 \\
\hline 10 & Pcs & Knot washer and lock washer & Php 1.00 & Php 10.00 \\
\hline $1 / 4$ & kl & Welding rod ordinary & Php 45.00 & Php 45.00 \\
\hline 50 & Pcs & Black screw & Php 1.00 & Php 50.00 \\
\hline 1 & Liter & Black paint & Php 100.00 & Php 100.00 \\
\hline & & Total & & Php17,450.00 \\
\hline
\end{tabular}

The table shown above is the Bill of Materials, Material Description and the Quantity.

Table4. Summary of project cost

\begin{tabular}{|c|c|}
\hline DESCRIPTION & PRICE (Php) \\
\hline Bill of Materials & Php17,450.00 \\
\hline Labor Cost & Php 6,500.00 \\
\hline Food and Transportation Expenses & Php 4,000.00 \\
\hline Grand Total & Php 27,950.00 \\
\hline
\end{tabular}

Table5. Gannt Chart showing the Schedule of the project

\begin{tabular}{|c|c|c|c|c|c|c|c|c|c|c|c|c|c|c|c|c|c|c|c|c|c|c|c|c|c|c|c|c|}
\hline \multirow{3}{*}{$\begin{array}{c}\text { MONTH } \\
\text { ACTIVITIES } \\
\end{array}$} & \multirow{2}{*}{\multicolumn{4}{|c|}{$\begin{array}{l}\text { NOVEMBER } \\
\text { WEEK \# }\end{array}$}} & \multirow{2}{*}{\multicolumn{4}{|c|}{$\frac{\text { DECEMBER }}{\text { WFEK\# }}$}} & \multicolumn{4}{|c|}{ JANUARY } & \multicolumn{4}{|c|}{ FEBRUARY } & \multicolumn{4}{|c|}{ MARCH } & \multicolumn{4}{|c|}{ APRIL } & \multicolumn{4}{|c|}{ MAY } \\
\hline & & & & & & & & & & WE & $\mathbf{L} \neq$ & & & WEI & EK\# & & & WEI & $\mathbf{K} \#$ & & & WE & & & & NEF & & \\
\hline & 1 & 2 & 3 & 4 & 1 & 2 & 3 & 4 & 1 & 2 & 3 & 4 & 1 & 2 & 3 & 4 & 1 & 2 & 3 & 4 & 1 & 2 & 3 & 4 & 1 & 2 & 3 & 4 \\
\hline $\begin{array}{l}\text { 1.Brainstormin } \\
\mathrm{g}\end{array}$ & & & & & 0 & 0 & & & II & & & 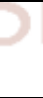 & & & & & 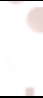 & & & & & & & & & & & \\
\hline $\begin{array}{l}\text { 2. Gathering } \\
\text { data in } \\
\text { selected } \\
\text { project }\end{array}$ & & & & se & & 8 & 0 & to & ITI & 2 & $\theta$ & nit & $\mathcal{J}$ & 10 & ind & nit & ell & $\theta$ & & 0 & & 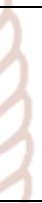 & & & & & & \\
\hline $\begin{array}{l}\text { 3.Project } \\
\text { proposal }\end{array}$ & & & & & & & & & D & $=$ & e & 0 & 01 & 10 & n1 & & & 0 & & & & 2 & & & & & & \\
\hline $\begin{array}{l}\text { 4. Designing } \\
\text { of the machine }\end{array}$ & & & & & & & & & & & 2 & & & 1 & & & & & 2 & & 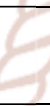 & & & & & & & \\
\hline $\begin{array}{l}5 . \quad \text { Gathering } \\
\text { and } \\
\text { Canvassing } \\
\text { materials }\end{array}$ & & & & & & & & & & & & & & & & & & & & & 7 & & & & & & & \\
\hline $\begin{array}{l}\text { 6.Fabrication } \\
\text { of the machine }\end{array}$ & & & & & & & & & & & & & & & & & & & & & & & & & & & & \\
\hline $\begin{array}{l}\text { 7. testing of } \\
\text { the machine } \\
\text { with controls }\end{array}$ & & & & & & & & & & & & & & $P$ & & & & & & & & & & & & & & \\
\hline $\begin{array}{l}8 . \\
\text { Commissionin } \\
\mathrm{g} \text { and Refining } \\
\text { adjustment }\end{array}$ & & & & & & & & & & & & & & & & & & & & & & & & & & & & \\
\hline $\begin{array}{l}\text { 9. Revision of } \\
\text { the Documents }\end{array}$ & & & & & & & & & & & & & & & & & & & & & & & & & & & & \\
\hline
\end{tabular}

The table above shows the procedures and schedule of the project from the month of November which Brain Storming up to month of May which is the Final. For the month of November up February the researchers planned and gathering all the materials needed and for the month of March up to third week of April the researching $\mathrm{s}$ fabricating the machine. 


\section{Results and Discussion}

The proposed study aimed to design and develop an "Electro-Pneumatic Sepak-Takraw Ball Pitching device" using the fluid power of compressed air. It is primarily concerned with designing an automatic pitching device that pitches the ball simultaneously; includes manual feature of the pitching controlled by another player; incorporates a pneumatic mechanism for the pitching device. It helps the Sepak-Takraw players to enhance the receiving and spiking skills. The device can pitch rubber ball or not with different angles, 360 degree in horizontal and 45 degree in vertical by adjusting the head manually. The head are removable for safe purpose if not in use. The device controlled manually by the push buttons located at the back of the machine or control automatically using a smartphone, tablet, ipad and laptop to the machine's Wi-Fi hotspot, it had 5 seconds interval in automatic pitching and a loud "pop" sound to give signal, to the player before pitching. The machine can pitch up to 5 ball before the re-loading of the reservoir or tank. The operator will also know if the machine is loaded or not by refreshing the smartphone app. The figure below shows the comparison of design and the actual photo of the device.
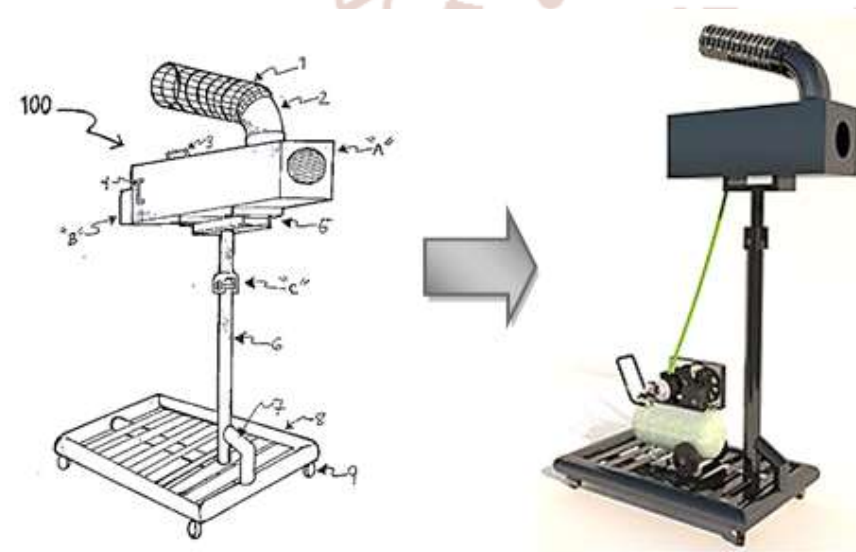

Figure8. Comparison between the design and the actual photo of the Electro-Pneumatic Sepak-Takraw Machine process

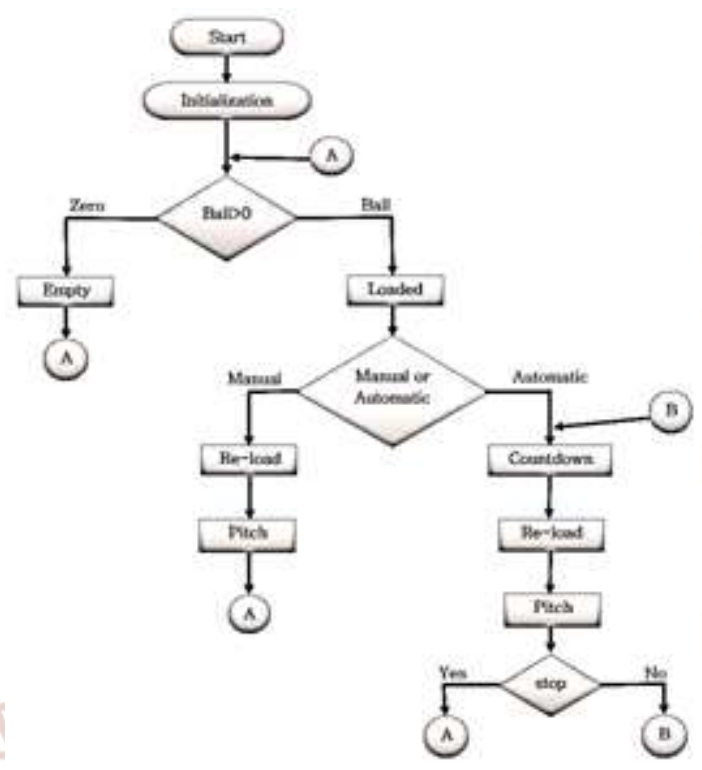

Figure9. Flowchart showing the Machine process The Flow chart of the machine process of project using Wi-Fi control

\section{Operational procedures}

1. Plug-in the compressor.

2. Plug-in the controls to the compressors outlet.

3. Load the hopper/re-loader with 5 takraw balls.
This picture will show in the web page after they enter the IP Address.
4. Switch on the controls.

5. Connect to the wifi.

6. Input the following to the smartphone. Name: Sepaktakraw Password: 123456789

7. Open browser and go to 192.168.4.1

8. Choose if you want automatic or manual.

9. You can now use the PITCHING MACHINE.

Safety and maintenance of the machine

1. Install the hose properly and tight.

2. Don't leave the compressor open when it's not use.

3. Remove the head of the machine when it is not use.

4. Lock the wheels before operating and using the machine.

5. Check the butterfly knot of the neck if loosen. 
Trials and Revision for Automatic function.

This trial and revisions shows the actual test of the researchers in the prototype's pitch test.

Table 6.Tossing (Automatic function)

\begin{tabular}{|c|c|c|c|c|}
\hline Tossing & Trial 1 & Trial 2 & Trial 3 & Results \\
\hline $1^{\text {st }}$ ball & Passed & Failed & Passed & Passed \\
\hline $2^{\text {nd }}$ ball & Passed & Passed & Passed & Passed \\
\hline $3^{\text {rd }}$ ball & Passed & Passed & Passed & Passed \\
\hline $4^{\text {th }}$ ball & Passed & Passed & Passed & Passed \\
\hline $5^{\text {th }}$ ball & Passed & Failed & Passed & Passed \\
\hline \multicolumn{4}{|c|}{ Overall } & Passed \\
\hline
\end{tabular}

\section{Legend:}

Passed - Achieved the end height of 3-6ft. with the distance of 12.2-16.2ft at the velocity of 10-20km/hr.

Failed- Neither of the speed, distanced or velocity were not achieved.

The table above were the trials of the actual device perform tossing operation using the automatic function. The legend shows the passing requirements for the pitch to have achieved end height of 3-6ft. with the distance of $12.2-16.2 \mathrm{ft}$ at the velocity of $10-20 \mathrm{~km} / \mathrm{hr}$ for tossing the ball.

Table7. Setting (Automatic function)

\begin{tabular}{|c|c|c|c|c|}
\hline Setting & Trial 1 & Trial 2 & Trial 3 & Results \\
\hline $1^{\text {st }}$ ball & Passed & Failed & & \\
\hline $2^{\text {nd }}$ ball & & $\mathrm{d}$ & & \\
\hline $3^{\text {rd }}$ ball & $\mathrm{Pas}$ & Fai & $\mathrm{Pa}$ & \\
\hline $4^{\text {th }}$ ball & $\mathrm{Pa}$ & $\mathrm{Pa}$ & & \\
\hline $5^{\text {th }}$ ball & Passed & Failed & & \\
\hline 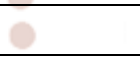 & \multicolumn{3}{|c|}{ Overall rech and } & sed \\
\hline
\end{tabular}

\section{Legend:}

Passed - Achieved the end height of 5-8ft. with the distance of $2-22 \mathrm{ft}$. at the velocity of $10-20 \mathrm{~km} / \mathrm{hr}$.

Failed- Neither of the speed, distanced or velocity were not achieved.

The table shown on the previous page were the trials of the actual device perform setting operation using the automatic function. The legend shows the passing requirements for the pitch to have achieved the end height of $5-8 \mathrm{ft}$. with the distance of $2-22 \mathrm{ft}$. at the velocity of $10-20 \mathrm{~km} / \mathrm{hr}$ for setting the ball.

Table8. Servicing (Automatic function)

\begin{tabular}{|c|c|c|c|c|}
\hline Servicing & Trial 1 & Trial 2 & Trial 3 & Results \\
\hline $1^{\text {st }}$ ball & Passed & Passed & Passed & Passed \\
\hline $2^{\text {nd }}$ ball & Passed & Passed & Passed & Passed \\
\hline $3^{\text {rd }}$ ball & Passed & Passed & Passed & Passed \\
\hline $4^{\text {th }}$ ball & Passed & Passed & Passed & Passed \\
\hline $5^{\text {th }}$ ball & Passed & Passed & Passed & Passed \\
\hline \multicolumn{4}{|c|}{ Overall } & Passed \\
\hline
\end{tabular}

\section{Legend:}

Passed - Achieved the end height of 3-6ft. with the distance of $13-37 \mathrm{ft}$. at the velocity of 50-80km/hr.

Failed- Neither of the speed, distanced or velocity were not achieved.

The table above were the trials of the actual device perform servicing operation using the automatic function. The legend shows the passing requirements for the pitch to have achieved the end height of 3-6ft. with the distance of $13-37 \mathrm{ft}$. at the velocity of $50-80 \mathrm{~km} / \mathrm{hr}$ for servicing the ball. 
Table9. Spiking (Automatic function)

\begin{tabular}{|c|c|c|c|c|}
\hline Spiking & Trial 1 & Trial 2 & Trial 3 & Results \\
\hline $1^{\text {st }}$ ball & Passed & Failed & Passed & Passed \\
\hline $2^{\text {nd }}$ ball & Failed & Passed & $\mathrm{Pa}$ & \\
\hline $3^{\text {rd }}$ ball & Passed & Passed & Passed & $\mathrm{Pa}$ \\
\hline $4^{\text {th }}$ ball & Passed & Failed & Passed & Passed \\
\hline $5^{\text {th }}$ ball & Passed & Pas & ed & ed \\
\hline \multicolumn{4}{|c|}{ Overall } & Passed \\
\hline
\end{tabular}

\section{Legend:}

Passed - Achieved the end height of 5-8ft. with the distance of 5-44ft. at the velocity of $20-70 \mathrm{~km} / \mathrm{hr}$.

Failed- Neither of the speed, distanced or velocity were not achieved.

The table above were the trials of the actual device perform spiking operation using the automatic function. The legend shows the passing requirements for the pitch to have achieved the end height of 5-8ft. with the distance of $5-44 \mathrm{ft}$. at the velocity of $20-70 \mathrm{~km} / \mathrm{hr}$ for spiking the ball.

\section{Trials and Revision for Manual function}

In the Manual feature, where the pitch is actuated by another player by pressing the push buttons for pitch and reload.

\section{Legend:}

Table10. Tossing (Manual function)

\begin{tabular}{|c|c|c|c|c|c|c|c|c|}
\hline \multirow{2}{*}{ Tossing } & \multicolumn{2}{|c|}{ TRIAL 1 } & \multicolumn{2}{c|}{ TRIAL 2 } & \multicolumn{2}{c|}{ TRIAL 3 } & \multicolumn{2}{c|}{ RESULTS } \\
\cline { 2 - 9 } & Reload & Pitch & Reload & Pitch & Reload & Pitch & Reload & Pitch \\
\hline $1^{\text {st }}$ ball & Passed & Failed & Failed & Passed & Passed & Passed & Passed & Passed \\
\hline $2^{\text {nd }}$ ball & Passed & Failed & Passed & Passed & Passed & Passed & Passed & Passed \\
\hline $3^{\text {rd }}$ ball & Passed & Passed & Failed & Passed & Passed & Passed & Passed & Passed \\
\hline $4^{\text {th }}$ ball & Passed & Failed & Passed & Passed & Passed & Passed & Passed & Passed \\
\hline $5^{\text {th }}$ ball & Passed & Passed & Failed & Passed & Passed & Passed & Passed & Passed \\
\hline \multicolumn{9}{|c|}{ Overall } \\
\hline
\end{tabular}

Passed - Reload: Single load of ball

Pitch: Achieved the end height of 3-6ft. with the distance of $12.2-16.2 \mathrm{ft}$ at the velocity of $10-20 \mathrm{~km} / \mathrm{hr}$..

Failed- Neither of the speed, distanced or velocity were not achieved.

The table on the above shows the trials of an actual device pitch-tossing in manual re-load and pitching of the ball. The legend shows the passing requirements for the pitch to have achieved the end height of 3-6ft. with the distance of $12.2-16.2 \mathrm{ft}$, at the velocity of $10-20 \mathrm{~km} / \mathrm{hr}$ for tossing the ball.

Table11. Setting (Manual function)

\begin{tabular}{|c|c|c|c|c|c|c|c|c|}
\hline \multirow{2}{*}{ Setting } & \multicolumn{2}{|c|}{ TRIAL 1} & \multicolumn{2}{|c|}{ TRIAL 2} & \multicolumn{2}{|c|}{ TRIAL 3} & \multicolumn{2}{|c|}{ RESULTS } \\
\hline & Reload & Pitch & Reload & Pitch & Reload & Pitch & Reload & Pitch \\
\hline $1^{\text {st }}$ ball & Failed & Passed & Passed & Passed & Passed & Passed & Passed & Passed \\
\hline $2^{\text {nd }}$ ball & Passed & Failed & Passed & Passed & Passed & Passed & Passed & Passed \\
\hline $3^{\text {rd }}$ ball & Failed & Passed & Passed & Passed & Passed & Passed & Passed & Passed \\
\hline $4^{\text {th }}$ ball & Passed & Failed & Passed & Passed & Passed & Passed & Passed & Passed \\
\hline $5^{\text {th }}$ ball & Passed & Passed & Passed & Passed & Passed & Passed & Passed & Passed \\
\hline \multicolumn{7}{|c|}{ Overall } & \multicolumn{2}{|c|}{ Passed } \\
\hline
\end{tabular}

\section{Legend:}

Passed - Reload: Single load of ball

Pitch: Achieved the end height of 5-8ft. with the distance of 2-22ft. at the velocity of $10-20 \mathrm{~km} / \mathrm{hr}$. Failed - Neither of the speed, distanced or velocity were not achieved. 
The table shown on the previous page were the trials of the actual device perform setting operation using the actuation of the manual buttons; re-load and pitch. The legend shows the passing requirements for the pitch to have end height of $5-8 \mathrm{ft}$ with the distance of $2-22 \mathrm{ft}$, at the velocity of $10-20 \mathrm{~km} / \mathrm{hr}$ for setting the ball.

Table12. Servicing (Manual function)

\begin{tabular}{|c|c|c|c|c|c|c|c|c|}
\hline \multirow{2}{*}{ Servicing } & \multicolumn{2}{|c|}{ TRIAL 1} & \multicolumn{2}{c|}{ TRIAL 2 } & \multicolumn{2}{c|}{ TRIAL 3 } & \multicolumn{2}{c|}{ RESULTS } \\
\cline { 2 - 9 } & Reload & Pitch & Reload & Pitch & Reload & Pitch & Reload & Pitch \\
\hline $1^{\text {st }}$ ball & Failed & Passed & Passed & Passed & Passed & Passed & Passed & Passed \\
\hline $2^{\text {nd }}$ ball & Passed & Failed & Passed & Passed & Passed & Passed & Passed & Passed \\
\hline $3^{\text {rd }}$ ball & Failed & Passed & Passed & Passed & Passed & Passed & Passed & Passed \\
\hline $4^{\text {th }}$ ball & Passed & Failed & Passed & Passed & Failed & Passed & Passed & Passed \\
\hline $5^{\text {th }}$ ball & Passed & Passed & Passed & Passed & Passed & Passed & Passed & Passed \\
\hline \multicolumn{9}{|c|}{ Overall } \\
\hline
\end{tabular}

\section{Legend:}

Passed - Reload: Single load of ball

Pitch: Achieved the end height of 3-6ft. with the distance of $13-37 \mathrm{ft}$. at the velocity of $50-80 \mathrm{~km} / \mathrm{hr}$.

Failed - Neither of the speed, distanced or velocity were not achieved.

The table shown above were the trials of the actual device perform servicing operation using the actuation of the manual buttons; re-load and pitch. The legend shows the passing requirements for the pitch to have achieved the end height of $3-6 \mathrm{ft}$. with the distance of $13-37 \mathrm{ft}$. at the velocity of $50-80 \mathrm{~km} / \mathrm{hr}$ for servicing the ball.

Table13. Spiking (Manual function)

\section{Legend:}

\begin{tabular}{|c|c|c|c|c|c|c|c|c|}
\hline \multirow{2}{*}{ Spiking } & \multicolumn{2}{|c|}{ TRIAL 1} & \multicolumn{2}{|c|}{ TRIAL 2} & \multicolumn{2}{|c|}{ TRJAL 3} & \multicolumn{2}{|c|}{ RESULTS } \\
\hline & Reload & Pitch & Reload & Pitch & Reload & Pitch & Reload & Pitch \\
\hline $1^{\text {st }}$ ball & Passed & Passed & Passed & Passed & Passed & Passed & Passed & Passed \\
\hline $2^{\text {nd }}$ ball & Passed & Passed & Passed & Passed & Passed & Passed & Passed & Passed \\
\hline $3^{\text {rd }}$ ball & Passed & Passed & Passed & Passed & Passed & Passed & Passed & Passed \\
\hline $4^{\text {th }}$ ball & Passed & Passed & Passed & Passed & Passed & Passed & Passed & Passed \\
\hline $5^{\text {th }}$ ball & Passed & Passed & Passed & Passed & Passed & Passed & Passed & Passed \\
\hline & 4 & 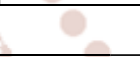 & Overall & & 70 & 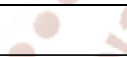 & $\mathrm{P}$ & \\
\hline
\end{tabular}

Passed - Reload: Single load of ball

Pitch: Achieved the end height of 5-8ft. with the distance of 5-44ft. at the velocity of $20-70 \mathrm{~km} / \mathrm{hr}$. Failed - Neither of the speed, distanced or velocity were not achieved.

The table shown on the previous page were the trials of the actual device perform spiking operation using the actuation of the manual buttons; re-load and pitch. The legend shows the passing requirements for the pitch to have achieved the end height of 5-8ft. with the distance of $5-44 \mathrm{ft}$. at the velocity of $20-70 \mathrm{~km} / \mathrm{hr}$ at the velocity of $50-80 \mathrm{~km} / \mathrm{hr}$ for servicing the ball.

\section{Conclusion}

Base on the trials and revision parameters of the pitching device for Sepak-Takraw, it was proven to have passed all the requirements both for the manual and automatic function in all of the operations. This means, the device is reliable when used repeatedly by the end-user which are the athletes.

\section{Recommendations}

Based on the results, analysis of the researchers, the following recommendations are highly suggested.
1. To the future researcher, based on the findings and testing the researcher needs to develop the automatic swing in left and right for the angle of the machine.

2. The researchers highly recommend to develop some device added to the machine to become more effective to the skill of the Sepak-Takraw players.

3. Researchers also recommend an oil-less/silent type compressor with big reservoir to effectively pitch the ball without delay. 
International Journal of Trend in Scientific Research and Development (IJTSRD) ISSN: 2456-6470

\section{BIBLIOGRAPHY}

1. Hamdan, N., Suwarganda, E., \& Wilson, B. (2012). Factors Correlated with Sepak Takraw Serve Speed. 30th Annual Conference of Biomechanics in Sports.

2. Jawis, M. N., Singh, R., Singh, H. J., \& Yassin, M. N. (2005). Anthropometric and physiological profiles of sepak takraw players. British Journal of Sports Medicine.

3. Kubo, Y., Nakazato, K., Koyama, K., Tahara, Y., Funaki, A., \& Hiranuma, K. (2016). The Relation between Hamstring Strain Injury and Physical Characteristics of Japanese Collegiate Sepak Takraw Players. International Journal of Sports Medicine.

4. Maseleno, A., \& Hasan, M. M. (2012). Fuzzy Logic Based Analysis of the Sepak Takraw Games Ball Kicking with the Respect of Player Arrangement. World Applied Programming.

5. Mubin, A. S. A., Ahmad, N., Mamat, A., Taha, Z., \& Hasanuddin, I. (2015). CFD Study of Drag and Lift of Sepak Takraw Ball at Different Face Orientations. Advances in Mechanical Engineering.

6. Parnabas, V. (2015). The effect of competitive state anxiety on sport performance among sepak takraw athletes. The International Journal of Indian Psychology ISSN.

7. Rashid AZIZ, A., Teo, E., Tan, B., \& Kong Oiuan, T. (2003). Sepaktakraw: A Descriptive Analysis of Heart Rate and Blood Lactate Response and Physiological Profiles of Elite Players. International Journal of Applied Sports Sciences.

8. Rezaei, M., Mimar, R., Paziraei, M., \& Latifian, S. (2013). Talent identification indicators in sepaktakraw male elite players on the bases of some biomechanical parameters. Middle East Journal of Scientific Research.

9. Silalertdetkul, S. (2016). Impact of sepak takraw practice on inflammatory markers in male athletes. Songklanakarin Journal of Science and Technology.

10. Sujae, I., Gon, K., \& Hin, M. (2008). Technology enhanced teaching and coaching of complex sport skills - An example of the acro-volley (sepaktakraw) power smash (kuda) and normal relay (sila) serve techniques. International Journal of Performance Analysis in Sport.

11. Taha, Z. (2008). A Study of the Impact of Sepaktakraw Balls on the Head. ISSN International Journal of Sports Science and Engineering.

\section{2.}

